\title{
Effect of Active Abdominal Compression-Decompression Cardiopulmonary Resuscitation on Oxygen Metabolism and Prognosis in Patients with Cardiac Arrest
}

\author{
Sha Xin ${ }^{1}$, Zhang Sisen ${ }^{1}$, Wang Hongwei ${ }^{1}$, Cen Yingxin ${ }^{1}$, Song Wei ${ }^{2}$, Li Jing ${ }^{3}$, Wang Lixiang ${ }^{4}$ \\ ${ }^{l}$ Department of Emergency and Critical Care Medicine, Zhengzhou People's Hospital, Zhengzhou, China \\ ${ }^{2}$ Hainan Provincial People's Hospital Emergency Medical Center, Haikou 570311, Hainan, China (Song W) \\ ${ }^{3}$ Beijing GMR Medical Equipment Company, Ltd. Beijing 100038, China (Li J) \\ ${ }^{4}$ Emergency Medical Center, China Armed Police General Hospital, Beijing 100039, China (Wang LX)
}

*Corresponding Author: Zhang Sisen, Department of Emergency and Critical Care Medicine, Zhengzhou People's Hospital Zhengzhou People's Hospital, Henan 450003, Zhengzhou, China, Email: 2362176700@qq.com

\begin{abstract}
Objective: To analysis effect of active abdominal compression-decompression cardiopulmonary resuscitation (AACD-CPR) and standard cardiopulmonary resuscitation (STD-CPR) on oxygen metabolism prognostic of cardiac arrest (CA), to evaluate treatment effect of $A A C D-C P R$.

Methods: Breathing, cardiac arrest patients without STD-CPR and AACD-CPR contraindications was collected from October 1, 2015 to May 31, 2017 in Zhengzhou people's Hospital, CA time less than 30 minutes, and all the patients were randomly divided into STD-CPR group and AACD-CPR group. All patients were given the same rescue measures, if required to give defibrillation defibrillation. STD-CPR group in accordance with the guidelines for CPR operation (2015 Edition), AACD-CPR group recovered using abdominal lifting and compression cardiopulmonary resuscitation instrument. Recording oxygen metabolism, hemodynamics and prognosis of two-group patients in the recovery process.
\end{abstract}

Results: A total of 69 cases, STD-CPR group of 34 cases, AACD-CPR group of 35 cases. (1)The oxygen metabolism: during the recovery, $A A C D-C P R$ group compared with STD-CPR group were significantly increased in arterial blood oxygen content (CaO2):15.6 \pm 1.5 to $14.2 \pm 1.9 \mathrm{~mL} / \mathrm{L}$, arteriovenous oxygen content difference (avDO2): $8.3 \pm 1.4$ to $7.3 \pm 1.3 \mathrm{~mL} / \mathrm{L}$, the oxygen carrying capacity (DO2) : $248 \pm 51$ to $208 \pm 54 \mathrm{~mL} / \mathrm{min}$, oxygen consumption (VO2) : $134 \pm 29$ to $118 \pm 32 \mathrm{~mL} / \mathrm{min}$, but no significant differences in cardiac output (CO) and mixed venous oxygen content (CvO2). (2) Hemodynamics: Two groups' base valueinthe heart rate (HR), mean arterial pressure (MAP), pH value, pulse oxygen saturation Degree (SpO2), arterial oxygen pressure $(\mathrm{PaO} 2)$, arterial partial pressure of carbon dioxide (PaCO2), lactate (Lac) were no significant differences. In the recovery process, MAP, $\mathrm{pH}, \mathrm{SpO} 2, \mathrm{PaO} 2$ of two groups increased, but PaCO2 and Lac decreased. Except MAP of STD-CPR group is slightly higher than AACD-CPR group, the change tendency of AACD-CPR group was more obvious in each index obviously [pH value: $0.10 \pm 0.15$ to $0.02 \pm 0.13$, SpO2 difference: $0.311 \pm 0.255$ to $0.159 \pm 0.232$, the difference in $\mathrm{PaO} 2(\mathrm{mmHg}, 1 \mathrm{mmHg}=0.133 \mathrm{kPa}): 12.96 \pm 21.84$ to $3.01 \pm 13.56$, the difference in $\mathrm{PaCO} 2$ ( $\mathrm{mmHg}$ ): $-9.91 \pm 11.17$ to $-3.52 \pm 13.87$, Lac value $(\mathrm{mmol} / \mathrm{L})$ : $-0.64 \pm 0.61$ to $-0.31 \pm 0.58]$. The prognosis: compared with STD-CPR group, the restoration of spontaneous circulation (ROSC) rate of $A A C D-C P R$ group was no increased slightly (22.9\% vs. $8.8 \%$ ), but the ROSC time of AACD-CPR group was

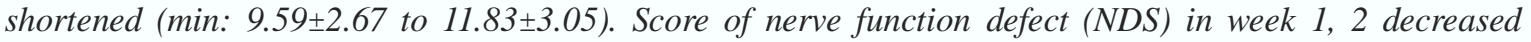
significantly (26.45 \pm 6.42 to $30.73 \pm 7.38 ; 19.25 \pm 6.27$ to $22.64 \pm 5.63$, respectively), and the two-week survival rate increased slightly $(17.1 \% 5.9 \%)$.

Conclusion: $A A C D-C P R$ is similar to STD-CPR in improving hemodynamics of CA patients, but has advantage in the blood oxygen supply of tissues and organs, and in the prognosis of patients with neurological function is better.

Keywords: Cardiopulmonary resuscitation, Abdominal compressure, Hemodynamics, Oxygen metabolism 


\section{INTRODUCTION}

Cardiopulmonary resuscitation (CPR) is an important measure in the treatment of patients with cardiac arrest (CA). Since the promotion of application in the 1950s, CPR has already gone more than 60 years of clinical practice. Although the rate of spontaneous circulatory recovery (ROSC) has been increased during the years, servival discharge rate, survival rate and quality of life were no significant improvement. It has been reported that after patients with successful CA recovery discharging, the one-year survival rate was only $20 \%$ [1]. Abdominal lifting and compressure cardiopulmonary resuscitation device achieves the cardiopulmonary resuscitation effect by increasing or reducing abdomen pressure of patients, which can be used for patients with chest compressions contraindications such as thoracodontal stab, Large blood vessel rupture [2]. At present, most studies focus on the change of hemodynamic indexes of abdomen CPR, but few studies on oxygen metabolism. Oxygen metabolism monitoring can observe the arterial and venous blood oxygen content, calculate the oxygen carrying capacity $\left(\mathrm{DO}_{2}\right)$ and oxygen consumption $\left(\mathrm{VO}_{2}\right)$, which reflect the metabolic status of the body, which can be used as an index to evaluate the effect of CPR [3,4]. The purpose of this study was to compare the effects of CPR on the oxygen metabolism and recovery in CA patients.

\section{MATERIAL AND METHODS}

\section{Ethical Approval}

The significance, safety, and constancy of the abdominal lifting and compression device used in this study have already been confirmed in animal and human experiments [5]. This study was approved by the Ethical Review Committee of Zhengzhou People' s Hospital. All patients' relatives and legal guardians all received a detailed interpretation on possible risks and benefits of the study and were permitted to request discontinuation of the study at any time. The requirements of the Declaration of Helsinki were strictly upheld throughout the research process.

\section{Patients}

From October 2015 to May 2017, 69 patients with respiratory and cardiac arrest who were treated in Zhengzhou people's Hospital. All patients were included in the following criteria: (1) loss of arterial pulsation, respiration, and consciousness, electrocardiogram showing ventricular fibrillation or straight line; (2) standard cardiopulmonary resuscitation (STD-CPR) and AACD-CPR were used; (3) the adult patients with a weight of $40 \sim 120 \mathrm{~kg}$, sex unlimited; (4) CA time less than $30 \mathrm{~min}$. Exclusion criteria: STD-CPR contraindications, (such as rib fractures, malignant tumor); AACD-CPR contraindications, (such as abdominal trauma, massive ascites).

\section{Interventions}

The patients were divided into STD-CPR group and AACD-CPR group according to the random digital table method. All patients were placed in tracheal intubation and Swan-Ganz catheter, artificial assisted ventilation, monitoring of vital signs, establishment of venous access, defibrillation by those who need defibrillate. Medical and nursing personnel involved in rescue and observation are strictly trained. STD-CPR group: operate according to the 2015 American Heart Association (AHA) CPR guide [6], press the frequency 100 120 times /min, press the depth of $5 \sim 6 \mathrm{~cm}$. AACD-CPR group: resuscitation was performed with abdominal lifting and compressure cardiopulmonary resuscitation device (CPR-LW1000).

\section{Termination rescue standard}

According to the AHA guidelines, meet the following requirements to terminate the rescue: (1) touching neck artery pulse; (2) the ruddy complexion; (3) visible thoracic fluctuation; (4) the great bulk of the pupil light reflex recovery. 
Effect of Active Abdominal Compression-Decompression Cardiopulmonary Resuscitation on Oxygen Metabolism and Prognosis in Patients with Cardiac Arrest

Rescue 30 min, if the patient breathing, circulation has not been restored, communication and family members of patients, to the consent of their families after the termination of treatment.

\subsection{Outcome Measurement}

\section{Oxygen metabolism}

Recording blood volume ( $\mathrm{CO}$ ), arterial oxygen content ( $\mathrm{CaO} 2)$, mixed venous blood oxygen content ( $\mathrm{CvO} 2$ ), dynamic - venous blood oxygen content difference ( avDO2), DO2, and $\mathrm{VO} 2$ in the center of resuscitation .

\section{Blood flow dynamics}

Recording resuscitation 1 min arterial blood gas as basic data, record blood pressure ( BP ), heart rate ( HR ) and arterial blood pressure every 5 minutes, and calculate mean arterial pressure ( MAP ) .

\section{Clinical prognosis}

Recording the ROSC rate, the time of ROSC, the clinical neurological impairment scoreat 1 week and 2 weeks and the 2 week survival rate.

\section{Statistical analysis}

Value were expressed as mean \pm standard deviation $(\mathrm{x} \pm \mathrm{s})$. $\mathrm{T}$ test was used to compare the data between groups and within groups, $\chi 2$ test used to rate comparison. The null-hypothesis was rejected for $\mathrm{P}<0.05$.

\section{RESUlT}

\subsection{General conditions of patients ( Table 1 )}

69 CA patients , 35 males , 34 females , 18-69 years old, average ( $44.8 \pm 8.7$ ) years old, AACD-CPR 35 cases, STD - CPR 34 cases . AACD-CPR group and STD-CPR group had no statistical significance $(\mathrm{P}>0.05)$.

Table1. Comparison of baseline data of CAA patients with cardiac arrest with different resuscitation methods

\begin{tabular}{|c|c|c|c|c|c|c|}
\hline \multirow[b]{2}{*}{ Group } & \multirow[b]{2}{*}{$\mathbf{N}$} & \multicolumn{2}{|c|}{ Gender（n) } & \multirow{2}{*}{$\begin{array}{c}\text { Age } \\
(\text { year, } x \pm s)\end{array}$} & \multirow{2}{*}{ BMI（kg/m2,x $\pm \mathrm{s})$} & \multirow{2}{*}{$\begin{array}{c}\text { CAtime } \\
(\min , \quad x \pm s)\end{array}$} \\
\hline & & Male & Female & & & \\
\hline STD-CPRgroup & 34 & 17 & 17 & $42.4 \pm 9.3$ & $62.16 \pm 15.49$ & $17.29 \pm 5.73$ \\
\hline AACD-CPRgroup & 35 & 18 & 17 & $45.1 \pm 9.0$ & $65.72 \pm 12.91$ & $19.84 \pm 6.51$ \\
\hline$t / \gamma 2$ value & & 0.014 & & -1.226 & -1.038 & -1.725 \\
\hline Pvalue & & 0.906 & & 0.225 & 0.302 & 0.089 \\
\hline
\end{tabular}

STD-CPR, standard cardiopulmonary resuscitation; AACD-CPR, active abdominal compressiondecompression cardiopulmonary resuscitation; BMI, body mass index.

\subsection{The oxygen metabolism index ( Table 2 )}

During CPR , the levels of $\mathrm{CaO} 2$, avDO2, $\mathrm{DO} 2$ and $\mathrm{VO} 2$ in AACD-CPR group were significantly higher than those in STD-CPR

Table2.Comparison of oxygen Metabolism Indexes during resuscitation between two groups of patients with Cardiac arrest and Cardiac arrest with different resuscitation methods $(x \pm s)$

\begin{tabular}{|c|c|c|c|c|}
\hline Group & $\mathbf{N}$ & $\mathbf{C O}(\mathbf{L} / \mathbf{m i n})$ & $\mathbf{C a O}_{\mathbf{2}}(\mathbf{m L} / \mathbf{L})$ & $\mathbf{C y}_{\mathbf{2}}(\mathbf{m L} / \mathbf{L})$ \\
\hline STD-CPR Group & 34 & $2.15 \pm 0.45$ & $142 \pm 19$ & $69 \pm 23$ \\
\hline AACD-CPR Group & 35 & $1.98 \pm 0.56$ & $156 \pm 15$ & $73 \pm 16$ \\
\hline tvalue & & 1.388 & -3.402 & -0.841 \\
\hline Pvalue & & 0.170 & 0.001 & 0.404 \\
\hline Group & $\mathbf{N}$ & $\mathbf{a v D O}_{\mathbf{2}}(\mathbf{m L} / \mathbf{L})$ & $\mathbf{D O}_{\mathbf{2}}(\mathbf{m L} / \mathbf{m i n})$ & $\mathbf{V O}_{\mathbf{2}}(\mathbf{m L} / \mathbf{m i n})$ \\
\hline STD-CPR group & 34 & $73 \pm 13$ & $208 \pm 54$ & $118 \pm 32$ \\
\hline AACD-CPR group & 35 & $83 \pm 14$ & $248 \pm 51$ & $134 \pm 29$ \\
\hline Tvalue & & -3.072 & -3.164 & -2.178 \\
\hline $\boldsymbol{P}$ value & & 0.003 & 0.002 & 0.033 \\
\hline
\end{tabular}

STD-CPR, standard cardiopulmonary resuscitation; AACD-CPR, active abdominal compression-decompression cardiopulmonary resuscitation; $\mathrm{CO}$, cardiac output; $\mathrm{CaO} 2$, arterial oxygen content; $\mathrm{CVO} 2$, mixed venous oxygen content; avDO2, arteriovenous oxygen content difference; DO2, oxygen load; VO2, oxygen consumption.

ARC Journal of Anesthesiology

Page $\mid 26$ 
Effect of Active Abdominal Compression-Decompression Cardiopulmonary Resuscitation on Oxygen Metabolism and Prognosis in Patients with Cardiac Arrest

\subsection{Hemodynamic indicators (Figure 1;} Table 3)

Before resuscitation, the two groups in HR, MAP, $\mathrm{pH}$ value, $\mathrm{SpO} 2, \mathrm{PaO} 2, \mathrm{PaCO} 2, \mathrm{Lac}$ were no significant difference (all $\mathrm{P}>0.05$ ). During the process of resuscitation, HR gradually recovered, the $\mathrm{pH}$ value, MAP, SPO2 and $\mathrm{PaO} 2$ showed an

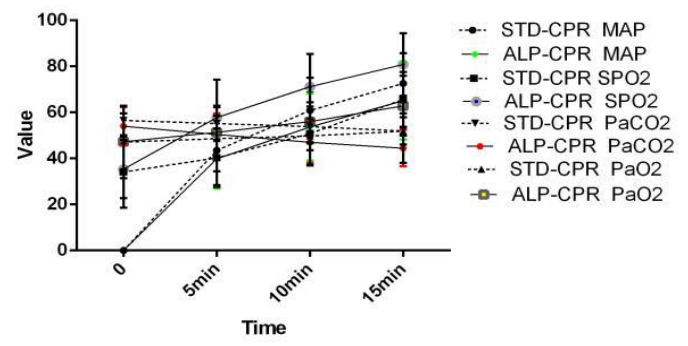

increasing trend, but $\mathrm{PaCO} 2$ and Lac showed an decreasing trend. The $\mathrm{pH}$ value, $\mathrm{SPO} 2$ and $\mathrm{PaO} 2$ of AACD-CPR group increased more rapidly and $\mathrm{PaCO} 2$ and Lac decreased more rapidly $(\mathrm{P}<0.05)$. The MAP of STD-CPR group was higher, but the difference was not statistically significant $(P>$ $0.05)$.

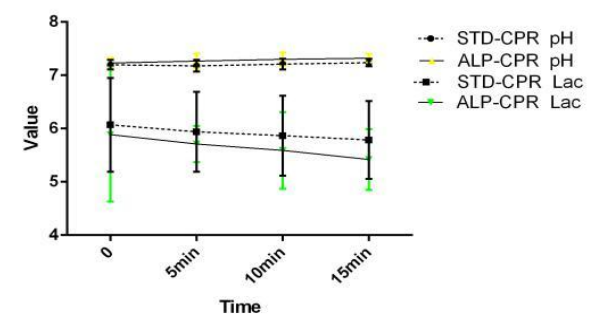

Figure1. Change trend of hemodynamics and arterial blood gas index during resuscitation in two groups of patients with cardiac arrest and CAA with different resuscitation methods

$S T D-C P R$, standard cardiopulmonary resuscitation; $A A C D$-CPR, active abdominal compression-decompression cardiopulmonary resuscitation; HR, heart rate; MAP, mean arterial pressure; SPO2, pulse oxygen saturation; $\mathrm{PaO} 2$, arterial partial pressure of oxygen; $\mathrm{PaCO}$, arterial partial pressure of carbon dioxide; Lac, lactate. 1 $m m H g=0.133 \mathrm{kPa}$

Table3.Comparison of hemodynamic and arterial blood gas index difference before and after resuscitation in two groups of cardiac arrest $(C A)$ patients with different resuscitation methods $(x \pm s)$

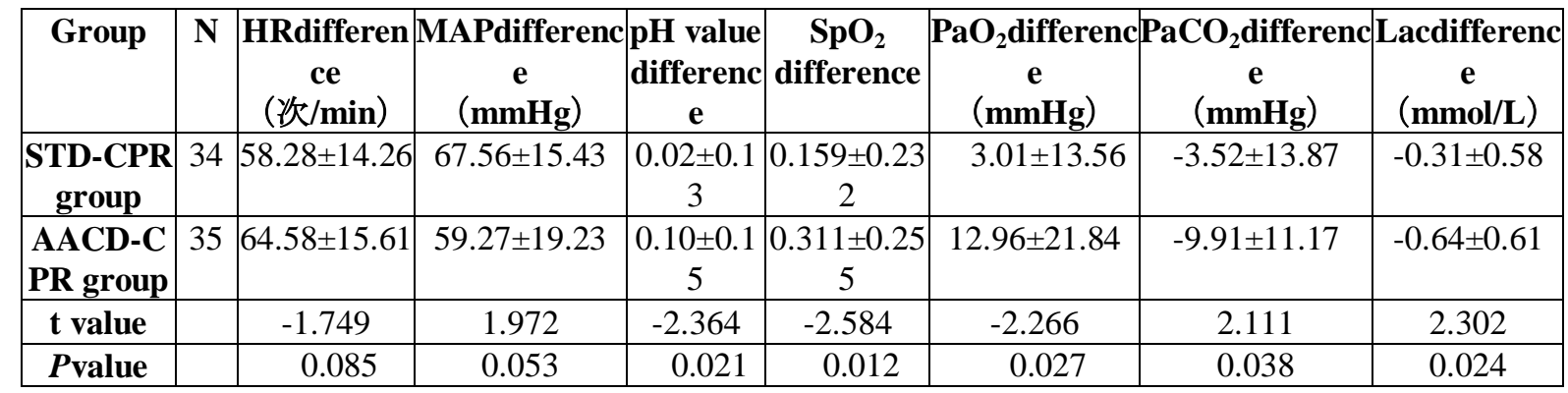

STD-CPR, standard cardiopulmonary resuscitation; AACD-CPR, active abdominal compressiondecompression cardiopulmonary resuscitation; $\mathrm{HR}$, heart rate; $\mathrm{MAP}$, mean arterial pressure; $\mathrm{SPO}_{2}$, pulse oxygen saturation; $\mathrm{PaO}_{2}$, arterial partial pressure of oxygen; $\mathrm{PaCO}_{2}$, arterial partial pressure of carbon dioxide; Lac, lactate. $1 \mathrm{mmHg}=0.133 \mathrm{kPa}$

\subsection{Clinical prognostic indicators (Table 4)}

Compared with STD-CPR group, ROSC time in AACD-CPR group was significantly earlier than that in ROSC1 group. The NDS decreased significantly at 1 -week and 2 -week $(\mathrm{P}<0.05)$. And ROSC rate and the 2-week survival rate increased, but the difference was not statistically significant ( $\mathrm{P}>0.05)$.

Table4.Comparison of clinical outcomes between two groups of cardiac arrest ( CA ) patients with different resuscitation methods $(x \pm s)$

\begin{tabular}{|c|c|c|c|c|}
\hline Group & $\mathbf{N}$ & ROSC rate $[\%$ (n) $]$ & ROSC time (min, $\mathbf{x} \pm \mathbf{s})$ & $\mathbf{2}$ - week survival rate $[\%(\mathbf{n})]$ \\
\hline STD-CPR group & 34 & $8.8(3)$ & $11.83 \pm 3.05$ & $5.9(2)$ \\
\hline AACD-CPR group & 35 & $22.9(8)$ & $9.59 \pm 2.67$ & $17.1(6)$ \\
\hline$\chi^{2} / \mathbf{t}$ value & & 2.535 & 3.249 & 2.133 \\
\hline $\boldsymbol{P}$ value & & 0.188 & 0.002 & 0.259 \\
\hline
\end{tabular}


Effect of Active Abdominal Compression-Decompression Cardiopulmonary Resuscitation on Oxygen Metabolism and Prognosis in Patients with Cardiac Arrest

\begin{tabular}{|c|c|c|c|}
\hline \multirow{2}{*}{ Group } & \multirow{2}{*}{$\mathrm{N}$} & \multicolumn{2}{|c|}{ NDS (score, $\mathbf{x} \pm$ s) } \\
\cline { 3 - 4 } & & one- week & two- week \\
\hline STD-CPRgroup & 34 & $30.73 \pm 7.38$ & $22.64 \pm 5.63$ \\
\hline AACD-CPRgroup & 35 & $26.45 \pm 6.42$ & $19.25 \pm 6.27$ \\
\hline$\chi^{2} /$ tvalue & & 2.572 & 2.361 \\
\hline Pvalue & & 0.012 & 0.021 \\
\hline
\end{tabular}

STD-CPR, standard cardiopulmonary resuscitation; $A A C D-C P R$, active abdominal compression-decompression cardiopulmonary resuscitation; ROSC, autonomic circulatory recovery; NDS, neurological deficit score.

\section{DISCUSSION}

The survival rate of patients with outhospital cardiac arrest (OHCA) from 2006 to 2010 was $8.2 \% \quad \sim 10.4 \%$ [7]. According to the epidemiological investigation in developed countries, the incidence of CA was still high, but the limitation of external pressure, facial defects, one - sidedness, lack of accurate and effective operation of rescue personnel resulted in a very low ROSC rate [8, 9].Chest in STD-CPR can not fully rebound, and not give sufficiently play to the effect of heart lung and lung pump and CPR success rate is limited[10]. Wang Lixiang 's team based on abdominal CPR, proposes the ALC-CPR new technique for restoring body size by pulling and pressing abdomen [11]; so as to achieve the effect of saving treatment .

Lee Sooman et al's [12] showed that the AACD-CPR group ROSC rate and the survival rate at sufficient was significantly higher than that of STD-CPR group. Liu Qing et al's [13] reported AACD-CPR ROSC rate was 20\%, and no abdominal organ injury, regurgitation and aspiration during the CPR; Zhu Jiang and Yang Guihua et al's [14] reported STD-CPR rate of ROSC $11 \%$, and the results of Zhang Zhenyu and Yu Xiaofanget al's [15] of ROSC $10.7 \%$. Several research results showed that AACD-CPR recovery effect is good, but more concentrated in the hemodynamics [16,17]. The premise of successful rescue of CA patients is to restore blood supply and correct abnormal oxygen metabolism. Therefore, the oxygen supply of the body and the oxygenation of tissues should not be ignored. Wuet al's [18] evaluated the effect of hypothermia on cerebral microcirculation after
$\mathrm{CPR}$ in Lac difference and $\mathrm{CO} 2$ difference of Internal jugular vein and its conclusion was that the high oxygen uptake rate indicated the microcirculation of the brain and the prognosis of the patients were good. Solevg et al's [19] showed the tissue oxygen saturation, $\mathrm{pH}$ and $\mathrm{Lac}$ as indicators of anaerobic metabolism may reflect the oxygenation and results of important organs. Oxygen metabolism monitoring reflected tissue hypoperfusion and tissue oxygenation function [20], and Li JW et al's [21] used oxygen metabolism index to reflect tissue oxygen supply, thereby to evaluate the effect of ECMO in treating ARDS, so it can be used as a method of evaluating the effect of resuscitation.

The results of this study show that STD-CPR CO is slightly higher than those of AACD-CPR, suggesting that pressing the thoracic cardiac ejection effect may be better. Previous studies have shown that compared with AACD-CPR, STD-CPR can provide higher MAP [22]. In this study, although MAP of STD-CPR group was slightly higher, but the AACD-CPR group in $\mathrm{CaO} 2, \mathrm{DO} 2, \mathrm{pH}$ value. $\mathrm{SpO} 2, \mathrm{PaO} 2$ was significantly higher than that of the STD-CPR, $\mathrm{PaCO} 2$, Lac decreased significantly, suggesting that AACD-CPR can provide better oxygen supply, which may be related to AACD-CPR's "four pump". The diaphragm moves up and down, the heart flexes and shrinks, reflecting the second pump of the heart and chest; At the same time, the changes of thoracic pressure, both breathing and blood circulation, reflect the lung and abdomen pump [10].Wang LX et al's [23] showed that AACD-CPR can provide higher tidal volume and the effect of auxiliary ventilation was better. Under pathological 
conditions, the oxygen demand of the body is increased greatly, and AACD-CPR can provide higher $\mathrm{CaO} 2 、 \mathrm{DO} 2 、$ avDO2. The results suggest that the utilization rate of oxygen in AACD-CPR group is higher than that in STD-CPR group, so AACD-CPR may be superior to STD-CPR in improving microcirculation. Liu Q et al's [24] also found that AACD-CPR can provide good hemodynamic and oxygen supply support. Spronk et al's[25] proposed the concept of " oxygen resuscitation in shock cells ", emphasized the improvement of body microcirculation and oxygen uptake, so AACD-CPR may be a new method of treating traumatic shock.

This study showed that AACD-CPR group ROSC earlier than in STD-CPR group, but no difference in the rate of ROSC, suggesting that recovery effect of the two way is quite similar to Wang Guotao et al's [26] research results. In addition, the AACD-CPR group's NDS score at one-week and two-week was significantly lower in group STD-CPR, indicating AACD-CPR on the prognosis of patients with neurological injury may be more excellent STD-CPR.

\section{CONCLUSION}

In summary, this study shows that AACD-CPR can achieve uninterrupted blood circulation and respiratory support both in hemodynamics and restoration of spontaneous circulation and the effect of STD-CPR is. AACD-CPR, to make up for the defects of STD-CPR can not take into account the breath, the tissue microcirculation oxygen supply and clinical prognosis has more advantages. But due to the limited number of cases collected less that part may be affected as a result, we need a multicenter clinical study further confirmed.

\section{REFERENCES}

[1] Bjørshol CA, Søreide E. Improving Survival after Cardiac Arrest [J]. Semin Neurol, 2017, 37 (1): 25-32. DOI: 10.1055/s-0036-1593890.

[2] Wang LX, Song W, Zhang SS, et al. ARC Journal of Anesthesiology
Multi-center clinical report of cardiopulmonary resuscitation with abdominal lifting and compression [J]. Chin J Emerg Med, 2017, 26 (3): 333-336. DOI: $10.3760 / \mathrm{cma}$.j.issn. 1 671-0282.2017.03.019.

[3] He ZJ, Guo XS, Chen D, et al. Oxygen metabolism during CPR in critically ill patients [J]. Chin J Emerg Med, 2001, 10 (6): 376-379. DOI: 10.3760/j.issn.1671-0282.2001.06.006.

[4] Ferradal SL, Yuki K, Vyas R, et al. Non-invasive Assessment of Cerebral Blood Flow and Oxygen Metabolism in Neonates during Hypothermic Cardiopulmonary Bypass: Feasibility and Clinical Implications [J]. Sci Rep, 2017, 7: 44117. DOI: 10.1038/srep44117.

[5] A. Morino, M. Shida, M. Tanaka et al., "Parameters affectingthe tidal volume during expiratory abdominal compression inpatients with prolonged tracheostomy mechanical ventilation," Journal of Physical Therapy Science,vol.27,no.7,pp.2167-2169,2015.

[6] Neumar RW, Shuster M, Callaway CW, et al. Part 1: Executive Summary: 2015 American Heart Association Guidelines Update for Cardiopulmonary Resuscitation and Emergency Cardiovascular Care [J]. Circulation, 2015, 132 (18 Suppl 2): S315-367. DOI: 10.1161/CIR.00 00000000000252.

[7] Nolan JP. Cardiac Arrest and Cardiopulmonary Resuscitation [J]. Semin Neurol, 2017, 37 (1): 5-12. DOI: 10.1055/s-0036-1597832.

[8] Shao SH. Progress on research of cardiocerebral resuscitation. Chin J Crit Care Med, 2017, 37(6): 572-576. DOI:10.3969/j.issn.1002-1949.2017. 06.023.

[9] Movahedi A, Mirhafez SR, Behnam-Voshani H, et al. A Comparison of the Effect of Interposed Abdominal Compression Cardiopulmonary Resuscitation and Standard Cardiopulmonary Resuscitation Methods on End-tidal $\mathrm{CO}_{2}$ and the Return of Spontaneous Circulation Following Cardiac Arrest: A Clinical Trial [J]. Acad Emerg Med, 2016, 23(4): 448-454. DOI: 10.1111/acem. 
12903.

[10] Li JK, Wang J, Li TF. Interposed abdominal compression-cardiopulmonary resuscitation after cardiac surgery [J]. Interact Cardiovasc Thorac Surg, 2014, 19 (6): 985-989. DOI: 10.1093/icvts/ivu255.

[11] Wang LX, Sun K, Ma LZ, et al. Effects of abdominal lifting and compression of chest pressure and chest compressions on pulmonary tidal volume of patients with cardiac arrest $\mathrm{J}$. Chin J Crit Care Med, 2009, 29 (9): 784-785. DOI : 10.3969/j.issn.1002-1949.2009.09.005

[12] Li XM, Wang LX, Liu YH, et al. An experimental study on the effects of rhythmic abdominal lifting and compression during cardiopulmonary resuscitation in a swine model of asphyxia [J]. Chin Crit Care Med, 2012, 24 (4): 237-240. DOI: 10.3760/cma.j.issn.20954352.2012.04.014.

[13] Li Q, Zhang SS, Peng DY, et al. Clinical observation on resuscitation effect of abdominal lifting and compression cardiopulmonary resuscitation [J]. Chin Crit Care Med, 2015, 27 (12):1011-1012. DOI:10.3760/cma.j.issn.20954352.2015.12.017.

[14] Zhu J, Yang GH. Treatment analysis of 90 cases of cardiac arrest [J]. Chin J TCM WM Crit Care, 2012, 19 (3): 187. DOI: 10.3969/j.issn.10089691.2012.03.023.

[15] Zhang ZY Yu XF. Clinical characteristics of sudden death outside hospital and effect of field intervention on resuscitation effect [J]. Chin J TCM WM Crit Care, 2011,18 (3): 184.DOI: 10.3969/j.issn.1008-9691.2011.03.025.

[16] Wang HW, Zhang SS, Sha X, et al. Clinical value of $\mathrm{P}_{\mathrm{ET}} \mathrm{CO}_{2}$ in evaluating efficacy of abdominal lifting and compression CPR: a report of 92 cases $[\mathrm{J} / \mathrm{CD}]$. Chin $\mathrm{J}$ Hygiene Rescue (Electronic Edition), 2017, 3 (2): 107-112. DOI: 10.3877/cma.j.issn.2095-9133. 2017.02.009.

[17] Wang HW, Sha X, Zhang SS, et al. Research progress of artificial circulation and ventilation of pre-hospital cardiopulmonary resuscitation
[J/CD]. Chin J Hygiene Rescue (Electronic Edition), 2017, 3 (2): 113-117. DOI: 10.3877/ cma.j.issn.2095-9133.2017.02.010.

[18] Wu J, Yuan W, Li J, et al. Effects of Mild Hypothermia on Cerebral Large and Small Microvessels Blood Flow in a Porcine Model of Cardiac Arrest [J]. Neurocrit Care, 2017, : DOI: 10.1007/s12028-017-0395-6.

[19] Solevåg AL, Schmölzer GM, Nakstad B, et al. Association between Brain and Kidney Near-Infrared Spectroscopy and Early Postresuscitation Mortality in Asphyxiated Newborn Piglets [J]. Neonatology, 2017, 112 (1): 80-86. DOI: $10.1159 / 000458515$.

[20] Xu X. The clinical significance of monitoring parameters for oxygen kinetics and metabolism in the diagnosis and treatment of shock [J]. Int $\mathrm{J}$ Pediatr, 2013, 40 (6): 621-624. DOI: 10.3760/ cma.j.issn.1673-4408.2013.06.023.

[21] Li JW, Liang HK, Wu GS, et al. Clinical application of extracorporeal membrane oxygenation in adult patients with acute respiratory distress syndrome. Chin J TCM WM Crit Care, 2017, 24(1):40-43. DOI : 10.3969/j. ssn.1008-9691.2017.01.013.

[22] Zhang S, Liu Q, Han S, et al. Standard versus Abdominal Lifting and Compression CPR [J]. Evid Based Complement Alternat Med, 2016, 2016: 9416908. DOI:10.1155/ 2016/ 9416908.

[23] Wang LX, Li XM, Guo CC, et al. Effect of abdominal lifting and compression cardiopulmonary resuscitation on pulmonary tidal volume in patients with respiratory depression under general anesthesia [J]. Chin Crit Care Med, 2015, 27(3):221-222. DOI: 10.3760/cma.j.issn.2095-4352. 2015.03.013.

[24] Li HQ, Wang LX, Liu YH, et al. Effect of abdominal lifting and compression cardiopulmonary resuscitation on hemo dynamics in pigs of cardiac arrest [J]. Chin Crit Care Med, 2011, 23 (10): 631-632. DOI: 10.3760/cma.j.issn.1003-0603.2011.10.018.

[25] Spronk PE, Zandstra DF, Ince C. Bench-to-bedside review: sepsis is a disease of 
Effect of Active Abdominal Compression-Decompression Cardiopulmonary Resuscitation on Oxygen Metabolism and Prognosis in Patients with Cardiac Arrest

the microcirculation [J]. Crit Care, 2004, 8 (6): 462-468. DOI: $10.1186 / \mathrm{cc} 2894$.

[26] Wang GT, Zhang SS, Li Q, et al. Clinical application of abdominal lifting and compression cardiopulmonary resuscitation: a report of 40 cases [J]. Chin J Emerg Med, 2015, 24 (11): 1264-1267. DOI:10.3760/cma.j.issn. 1671-0282.2015.11.018.

Citation: Michaela Wilhelmi, Mathias Wilhelmi, Christian Krettek, Frank Hildebrand, Hagen Andruszkow, Alexander A. Hanke, Felix Flöricke. Effect of Active Abdominal Compression-Decompression Cardiopulmonary Resuscitation on Oxygen Metabolism and Prognosis in Patients with Cardiac Arrest. ARC Journal of Anesthesiology. 2017;2(4):24-31. doi: dx.doi.org/10.20431/2455-9792.0204004.

Copyright: (c) 2017 Authors. This is an open-access article distributed under the terms of the Creative Commons Attribution License, which permits unrestricted use, distribution, and reproduction in any medium, provided the original author and source are credited. 